Данькин Михаил Анатольевич

аспирант Московского государственного университета им. М.В. Ломоносова

\section{ФАКТОРЫ ВОЗНИКНОВЕНИЯ СОЦИОКУЛЬТУРНЫХ ПРОТИВОРЕЧИЙ В МОЛОДЕЖНОЙ СРЕДЕ}

Аннотация:

Статья посвящена изучению факторов образования социокультурных противоречий в молодежной среде. На основании группы факторов, участвующих в формировании ценностных ориентаций представителей молодого поколения, контекста места и времени рассмотрения социокультурных противоречий проводится исследование причин возникновения конфликта общества и культуры в среде молодежи. В работе анализируются ключевые особенности информационного социума, которые непосредственным образом влияют на наличие тех или иных факторов. Коммуникационные способности индивидов, возросшая роль массового общества, а также государственная политика в области культуры определены как существенные составляющие процесса возникновения социокультурных противоречий. Социокультурная идентичность индивидов трактуется как важный компонент социокультурного анализа. Найдены и определены факторы генезиса социокультурных разногласий, управление которыми позволит регулировать социокультурный процесс.

Ключевые слова:

факторы социокультурных противоречий, социокультурная идентичность, социокультурные противоречия, социокультурный подход, социокультурный конфликт, социокультурная среда, молодежь, модернизация общества.
Dankin Mikhail Anatolyevich

PhD student,

Lomonosov Moscow State University

\section{THE DRIVERS OF SOCIAL AND CULTURAL CONTRADICTIONS AMONG YOUNG PEOPLE}

Summary:

The study deals with the drivers of social and cultural contradictions among the youth. Based on a group of factors in the development of youth values, the place and time of the consideration of social and cultural contradictions, the research examines the causes of the conflict between society and culture among young people. The study analyzes the key aspects of the information society that have a direct impact on the availability of different drivers. Communication skills of individuals, the increased role of mass society, and state cultural policy are defined as pivotal elements of social and cultural contradictions. The social and cultural identity of individuals is regarded as an important component of social and cultural analysis. The drivers of social and cultural contradictions are identified and determined. Their management will allow one to regulate the social and cultural process.

Одна из важнейших задач, стоящих перед исследователями теорий конфликта, состоит в понимании того, чем является данный феномен: условием модернизации общественных отношений или фрактором, разрушающим общество. Теория конфликта содержит два основных направления, которые призваны дать ответы на этот вопрос: структурный функционализм (Г. Спенсер, Т. Парсонс, Р. Мертон, Г. Зиммель и др.) и конфликтный подход (К. Маркс, Р. Дарендорф, Р. Коллинз и др.).

Структурный функционализм рассматривает конфликт как дисфункцию системы. При этом противоречия нарушают привычный уклад жизни общества и вводят в дестабилизацию социальных отношений, что обусловливает нарушение баланса, устойчивости общества. Конфликтный подход исследует иную сторону социальных противоречий. В данном случае конфликт служит потенциалом для обновлений, которые позволяют социуму успешно развиваться и воспроизводить социальные отношения.

Конфликтные ситуации могут быть порождены личностными противоречиями, антагонистическим взглядом на предмет общественных отношений. Под противоречием личностных ценностей здесь необходимо понимать взаимодействие противоположных ценностей, находящихся во внутреннем единстве [1]. Следовательно, изучение факторов противоречий следует начинать с рассмотрения факторов, определяющих формирование самих ценностей.

Например, с точки зрения Е.И. Салгановой, существуют объективные фракторы становления ценностных ориентаций [2]:

- уровень жизни семьи, образование родителей;

- СМИ, формирующие образ индивида в общественном мнении;

- государство и институты власти;

- семья;

- рефрерентная группа (друзья, знакомые, коллеги); 
- кризис ценностей и норм в социуме;

- отсутствие гражданского общества и правового государства;

- молодежные общественные объединения.

Наряду с объективными факторами ценностные ориентации формируются и при воздействии субъективных фракторов:

- гражданских качеств;

- общественной активности;

- интереса к гражданским знаниям.

Согласно Г.С. Голошумовой и С.Г. Ежову, существует иная классификация, включающая внешние и внутренние фракторы [3]. Внешние фракторы затрагивают следующие сферы:

- психолого-педагогические,

- социальные,

- экономические,

- демографические,

- социокультурные.

Внутренним факторам соответствуют специфические особенности изучаемого объекта:

- отличительные черты подросткового возраста,

- субкультура подростка,

- социальный опыт,

- ценностные ориентации,

- потребности,

- мотивация.

Ценности определяют уровень социокультурного сознания человека, а потому имеют ключевое значение в механизме возникновения социокультурных противоречий. Молодежь как самая активная социальная группа является максимально восприимчивым структурным элементом общества, который подвержен противоречиям. Социальные процессы существенно воздействуют именно на молодежь, а потому рассмотрение факторов противоречий наиболее актуально в данной социальной группе. Различие подходов к установлению условий, определяющих ценности человека, позволяет понять, сколь многогранными могут быть предпосылки развития социокультурных конфликтов в среде молодежи. На основании аспектов, влияющих на ценностную систему человека и, следовательно, оказывающих воздействие на становление противоречий в целом, необходимо выявить фракторы, фрормирующие социокультурные противоречия молодежи в частности.

Данный анализ невозможен без рассмотрения контекста времени, в котором происходят социокультурные процессы. Информационное общество в первую очередь характеризуется возросшей коммуникационной способностью индивидов, а также преобладанием массовой культуры над традиционной и элитарной. Этот факт позволяет изучать социокультурную динамику при непосредственном участии указанных параметров.

Усиление ресурсов средств и каналов коммуникации увеличивает возможность передачи данных, что приводит к изменениям в социокультурной динамике, скорости распространения информации, а потому позволяет ей становиться достоянием большого количества людей практически мгновенно. Общественные отношения подвергаются регуляции каналами коммуникации, при помощи которых осуществляется информационный обмен. В подобной ситуации сложно отделить взаимодействия внутри общества от банального обмена сведениями [4, с. 57]. Скорость коммуникации в молодежной среде оказывает катализирующее воздействие на факторы социокультурной динамики, что порождает новые феномены. Этот факт приводит к возрастанию рефрлексивных и нерефлексивных социальных рисков.

Рассматривая массовое общество как часть социокультурной динамики, можно найти ответ на вопрос о массовой культуре в становлении социокультурных противоречий. Используя методологию социокультурного подхода, мы отходим от оценочных суждений и имеем возможность воспринимать формирование массовой культуры в качестве органической части исторического процесса, а не как отклонение от «нормального» состояния общества.

Массовое общество можно охарактеризовать не подлинной социальной активностью, которая направлена на конструктивный диалог, а некой симуляцией данной активности [5], позволяющей обеспечить пребывание социума в состоянии аномии. В данной ситуации социокультурные противоречия приобретают латентный характер, а потому индивид имеет возможность получить новый способ социализации или его симуляцию.

Массовое общество с преобладающим общественным мнением становится одним из главных фракторов преобразований и катализатором социокультурной динамики. Данный факт иллюстрирует то, как информация приобретает значимость только в ситуации соответствия ожиданиям и запросам массы. Таким образом, масса не может решить социокультурных противоречий, а лишь делает их менее явными, приводя проблему к стандартам общественного мнения. 
Совместно с коммуникацией и массовым обществом в значительной степени на факторы возникновения социокультурных противоречий воздействует государственная политика в области взаимодействия культуры и общества, которое выражается в обоюдном влиянии на социальную систему: социокультурные ориентации индивидов меняются под действием реформ, а на проводимых реформах прямым образом сказываются изменения в культуре. Новые инициативы государства не всегда принимаются членами социума благосклонно, а потому с высокой долей вероятности ведут к рассогласованию интересов различных общественных категорий, а также к непринятию новых социокультурных образцов поведения.

Реформы должны зиждиться на культурных предпосылках, а именно на общепризнанных ценностях и нормах. В ситуации, когда политика осуществляется без учета социокультурных предпосылок, возникают противоречия.

На основании фракторов, определяющих формирование ценностей молодых людей, а также учитывая главные характеристики временно́го контекста рассмотрения проблематики социокультурных противоречий, выделим фракторы становления социокультурных противоречий в молодежной среде.

- Размытие общечеловеческих ценностей и понятия нравственности. Изменение традиционных представлений о нравственности приводит к рассогласованию интересов разных групп молодежи. Данный факт иллюстрирует ситуацию, при которой представители одной возрастной группы имеют диаметрально противоположную точку зрения на один предмет общественных отношений.

- Деформация ценностей, произошедшая на этапе смены поколений. Ценностные ориентации, будучи привычными для одного поколения людей, не разделяют представители более молодого поколения, в результате чего нарастают противоречия в социокультурной среде общественных отношений.

- Ускоренный процесс глобализации и урбанизации, повышение скорости социальных изменений. Ускорение социальных, культурных, экономических и политических процессов в обществе ведет к смещению ориентиров и невозможности индивидов быстро реагировать на преобразования. Социальные трансформации происходят быстро и за короткий период, что приводит к кризису жизненных ожиданий.

- Возрастающая роль информационного пространства, развитие сети Интернет. Виртуальные отношения преобладают над реальными, что обусловливает смещение вектора подлинной социальной активности. Виртуальная реальность становится более востребованной для социализации молодежи средой, в то время как общественные процессы проходят преимущественно в среде реальной. Социализируясь в виртуальном пространстве, индивид испытывает трудности в постижении действительных отношений.

- Общественное мнение. Мнение большинства может как утвердить положение индивида и его взгляды в обществе, так и привести к маргинализации и затруднению социализации.

- Деформация образа государственных институтов. Неспособность государственных институтов разрешать проблемы представителей общества ведет к потере авторитета власти и увеличению роли конкретных личностей. Индивид все больше берет на себя ответственность за личную жизнь и жизнь близких.

- Отсутствие общей идеологии. Размытие вектора развития и ценностей государства как социокультурной общности людей обусловливает утрату ориентиров развития и ценностных смыслов в формате группы. Индивидуалистические цели превалируют над коллективными.

- Непрерывный процесс реформирования общественных структур, проходящий при игнорировании реальных потребностей общества, особенностей менталитета, культуры. Отсутствие четких сроков реализации государственных программ, социальных гарантий и перспектив в средне- и дальнесрочной перспективах.

- Увеличение контроля государства за частной жизнью граждан, СМИ, общественными институтами приводит к утрате чувства личной безопасности и неприкосновенности индивида.

- Несоответствие условий внешней среды. Кризис несоответствия стремлений и фактических возможностей индивида иллюстрирует несовершенство пенсионной, образовательной, медицинской и других систем.

Данные факторы возникновения социокультурных противоречий могут быть характерны не только для представителей молодежной среды, однако именно молодежь, будучи наиболее активной социальной группой, находящейся в процессе активной социализации, в максимальной степени подвержена их влиянию [6].

Рассмотрение факторов возникновения социокультурных противоречий возможно исключительно в совокупности с контекстом места и времени, в которых исследуются социокультурные противоречия. В противном случае существует риск ложного определения как самих противоречий, так и фракторов, их фрормирующих. 
Определение контекста связано с особенностями историко-географического развития, социальной, экономической, политической и идеологической составляющими развития общества. Данные параметры находят отражение в социокультурных характеристиках, которые именуются социокультурной идентичностью индивидов. Именно она непосредственно влияет на совокупность факторов формирования противоречий общества и культуры в молодежной среде. Социокультурная идентичность не может разрешить данную проблему, как и нивелировать ее влияние, однако она способна помочь исследователю выявить эти фракторы и предупредить развитие социокультурного конфликта.

\section{Ссылки:}

1. Капцов А.В. Изучение предикторов динамики личностных качеств субъектов взаимодействия // Вестник Самарской гуманитарной академии. Сер.: Психология. 2011. № 2 (10). С. 146-157.

2. Салганова Е.И. Гражданская культура учащейся молодежи: социологический анализ : автореф. дис. ... канд. социол. наук. Екатеринбург, 2008. 22 с.

3. Голошумова Г.С., Ежов С.Г. Факторы формирования социальной компетентности подростка // Педагогическое образование в России. 2011. № 4. С. 211-217.

4. Печенкин В.В. Информационные технологии в социальной структуре общества. Саратов, 2001. 185 с.

5. Bauman Z. Liquid Modernity. Cambrige, 2000. 240 p.

6. Robertson R. Globalization: Social Theory and Global Culture. L., 1992. 224 p.

\section{References:}

Bauman, Z 2000, Liquid Modernity, Cambrige, 240 p.

Goloshumova, GS \& Ezhov, SG 2011, 'Factors of Formation of Social Competence of a Teenager', Pedagogicheskoye obrazovaniye $v$ Rossii, no. 4, pp. 211-217, (in Russian).

Kaptsov, AV 2011, 'The Study of Predictors of the Dynamics of Personal Qualities of the Subjects of Interaction', Vestnik Samarskoy gumanitarnoy akademii. Ser.: Psikhologiya, no. 2 (10), pp. 146-157, (in Russian).

Pechenkin, VV 2001, Information Technology in the Social Structure of Society, Saratov, 185 p., (in Russian).

Robertson, R 1992, Globalization: Social Theory and Global Culture, London, 224 p.

Salganova, El 2008, Civic Culture of Studying Youth: a Sociological Analysis, PhD thesis abstract, 22 p., (in Russian). 